\title{
OUVIDORIA-GERAL DO MUNICÍPIO DO RECIFE: EXEMPLO DE INOVAÇÃO NA GESTÃO PÚBLICA
}

\author{
Izabela Mendes de Oliveira ${ }^{1}$
}

\section{Resumo}

A finalidade deste artigo é demonstrar a Inovação da Gestão Municipal do Recife, após a inauguração da Ouvidoria-Geral do Município do Recife, apresentando todo o processo de implantação e as diversas ferramentas utilizadas para oferecer à população uma Ouvidoria inovadora que visa contribuir para o canal de comunicação e participação social e expandi-lo. O breve histórico dos diversos conceitos facilitará compreender como aliar teoria e prática em organizações públicas, propiciando resultados eficazes nas implantações de Ouvidorias.

Palavras-chave: Ouvidoria. Sistemas. Gestão. Participação Social.

\begin{abstract}
The purpose of this article is to demonstrate the innovation of the municipal management of Recife after the inauguration of the General Ombudsman's Office of the Municipality of Recife, presenting all the implementation process and the various tools used to present the population an innovative Ombudsman's Office that aims to contribute to the channel of communication and social participation and expand it. The brief history of the various concepts will facilitate understanding how to combine theory and practice in public organizations, providing effective results in the ombudsmanship's deployments.
\end{abstract}

Keywords: Ombudsman's Office. Systems. Management. Social Participation.

\section{DOI:10.37814/2594-5068.2018v1.p209-217}

1 Graduada em Marketing pela Faculdade Boa Viagem (FBV). Especialista em Gestão de Ouvidorias pela Escola Superior de Relações Públicas (ESURP). Formação em Gestão e Implantação de Ouvidoria pela Faculdade de Ciências e Administração Pública (FCAP). Curso de Capacitação Profissional em Ouvidoria pela Universidade de Brasília (UNB). Consultora Organizacional. Atualmente exerce o cargo de Ouvidora-Geral do Município do Recife.

(izabelape@hotmail.com) 


\section{INTRODUÇÃO}

A Ouvidoria-Geral do Município do Recife - OGMR - é um importante instrumento oferecido à população como canal de comunicação participativa, por meio do qual o cidadão e/ou servidor pode contribuir para a melhoria da gestão pública. A Ouvidoria está vinculada à Secretaria de Governo e Participação Social, que tem por finalidade e competências: atuar no relacionamento com a sociedade civil e gerenciar os mecanismos de Participação Social da Prefeitura da Cidade do Recife; monitorar e promover a transparência da gestão, bem como coordenar a política de comunicação institucional do município; exercer a coordenação das atividades entre os órgãos e entidades do Poder Executivo Municipal, concernentes aos aspectos administrativos, políticos, cívicos e de representação; além de publicar os atos, despachos e expedientes da Prefeitura.

A Prefeitura do Recife optou por não implantar o SAC, Serviço de Atendimento ao Consumidor, decidindo, portanto, oficializar a Ouvidoria-Geral, que tem a competência de analisar, encaminhar e monitorar as manifestações e todo o seu andamento, fortalecendo a gestão participativa.

Para atender com qualidade o cidadão e/ou servidor conta com uma equipe técnica especializada de assessores, assistentes e teleatendentes coordenados pelo Ouvidor-Geral do Município do Recife.

\section{OBJETIVOS DA OUVIDORIA-GERAL DO MUNICÍPIO DO RECIFE}

A Ouvidoria tem como objetivos: proporcionar um melhor entendimento e acompanhamento das manifestações (transparência) a partir de um modelo estruturado; promover a melhoria da participação popular, aproximando a população da gestão pública, buscando facilitar e intermediar a visualização dos responsáveis nesses processos; capacitar e treinar servidores, visando a melhoria no atendimento ao público; registrar e documentar para consultas e orientações futuras; assegurar o direito do cidadão atuar como instrumento de participação e intermediar a relação da sociedade com a gestão inovando na melhoria dos processos e eficiência na execução dos serviços públicos para o cidadão.

\section{AMBIENTE ANTERIOR À IMPLANTAÇÃO DA OUVIDORIA}

Com o levantamento inicial de informações por meio do Diagnóstico Institucional, pôde-se constatar que a administração municipal, anteriormente, disponibilizava um canal de interação social hospedado no portal da Prefeitura, através do qual eram inseridas manifestações que seguiam para o setor de comunicação/imprensa da Prefeitura da Cidade do Recife - PCR. Algumas Secretarias também atendiam o cidadão e/ou servidor de forma descentralizada, sem integração e monitoramento dos fatos recebidos. As manifestações não obedeciam a procedimentos para seus encaminhamentos, sendo aleatoriamente respondidas, por falta primordialmente de pessoal para análise, encaminhamentos, respostas e contato com o cidadão e/ou servidor manifestante. Identificou-se 
também o grande lapso temporal para possíveis respostas, o que descredenciava o serviço para seu objetivo em primeira instância, o de oferecer ao cidadão e/ou servidor manifestante a oportunidade de expressar-se diante da constatação de ações propositivas e/ou que necessitariam de correções e ajustes para atingir eficácia nos resultados propostos.

\section{JUSTIFICATIVA DA GESTÃO MUNICIPAL}

A iniciativa do Governo Municipal em implantar a Ouvidoria surgiu da necessidade de disponibilizar um canal efetivo de ausculta que estimulasse a participação popular e, com base nas manifestações recebidas, identificasse seus anseios e melhorias dos serviços prestados à cidade pela Prefeitura do Recife.

Segundo VIANA JÚNIOR (2007, p. 4), nas Ouvidorias mais modernas o cidadão é incentivado a fazer uso de todas as oportunidades para desenvolver melhores relacionamentos com o serviço público. Os clientes são levados nesta direção no decorrer de toda a transação e são educados acerca de novos padrões de relacionamento. É importante que a Ouvidoria faça o marketing para conscientização e aproximação do seu público-alvo.

A Ouvidoria trabalha para garantir atendimento de excelência a todo cidadão e/ou servidor por meio do processo de constante aprimoramento das ações, visando estabelecer uma relação transparente, para juntos construirmos um Recife melhor.

Tendo em vista uma melhor compreensão e entendimento de todo o processo utilizado pela OGMR, Ouvidoria-Geral do Município do Recife, concernente ao trâmite das manifestações, observou-se a necessidade da construção do Mapeamento de Processo; Elaboração de Termo de Conduta Interno; Criação da Cartilha de Atendimento ao Cidadão; Divulgação dos contatos da Ouvidoria em todas as propagandas do município e nos carros oficiais; Criação de aplicativo para smartphones facilitando a comunicação e ampliando os serviços e canais de comunicação; Capacitação contínua da equipe de atendimento; e a Ouvidoria Itinerante para atender o público interno e externo. Todas essas iniciativas reforçam o sentimento de transparência das ações implementadas pela gestão municipal.

Com a proposição da estruturação de uma unidade ouvidora, o município passa a atuar de forma proativa, eficiente, com procedimentos, prazos e encaminhamentos direcionados às áreas de competência, cobrando respostas, oferecendo as soluções e análises das manifestações registradas em um sistema único, com condições de monitorar e disponibilizar relatórios gerenciais que subsidiam a gestão por meio das manifestações recebidas, propondo ações de melhoria e ajustes naquelas demandas em andamento, como também nas ações que já estão funcionando.

Toda essa gama de procedimentos adotados está devidamente regulamentada a partir da inauguração da Ouvidoria, por meio de legislação própria sancionada (Decreto 28.555, de 28 de janeiro de 2015), e legitimada pelo cidadão e/ou servidor manifestante.

Diante deste contexto, foi possível identificar que a importância de implantar uma Ouvidoria passa pela necessidade de oferecer um canal entre a população e o governo que promova a participação do cidadão e/ou servidor enquanto sujeito de direito. 


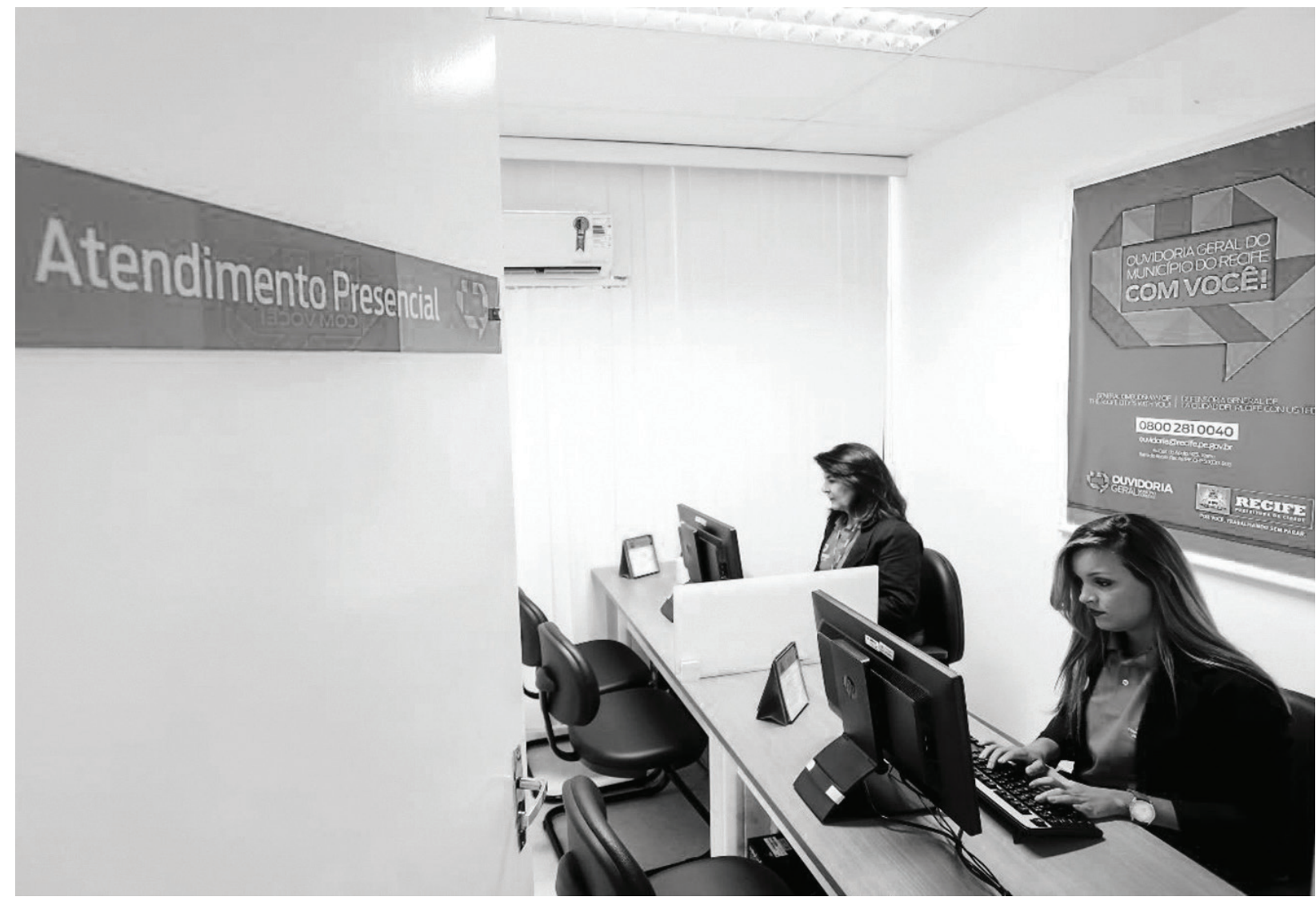

\section{ADOÇÃO DE UM SISTEMA INTEGRADO DE GESTÃO DE OUVIDORIAS}

A plataforma tecnológica definida foi a dotada de ferramentas de última geração, desenvolvida por uma empresa pernambucana e adquirida por meio de licitação, juntamente com cessão do código-fonte, incluindo uma ferramenta de Business Intelligence $(\mathrm{BI})$ para a extração de diversos indicadores, de modo a possibilitar a tomada de decisões gerenciais e estratégicas mais ágeis por parte dos gestores da Prefeitura da Cidade do Recife.

De maneira mais técnica, sistemas de informação podem ser definidos como "qualquer sistema utilizado para prover informações qualquer que seja sua utilização" (POLLONI, 2000, p. 30). Já, sob o ponto de vista processual, "sistemas de informação são processos administrativos que envolvem processos menores que interagem entre si” (MATSUDA, 2010). Desta forma, o software utilizado para sistematizar as informações da Ouvidoria atende aos procedimentos operacionais necessários para operação e gestão de uma Ouvidoria-Geral, com interação total com os interlocutores nas secretarias municipais e demais órgãos.

Possui telas específicas para registro e consulta aos atendimentos de acordo com os perfis: Chefe de Atendimento ou Ouvidor/assistentes (presencial), Teleatendimento (0800) e Portal de Autoatendimento (para usuários da internet) permitindo múltiplos tipos de atendimento, sem obrigatoriedade de cadastro prévio ou participação em redes sociais; 


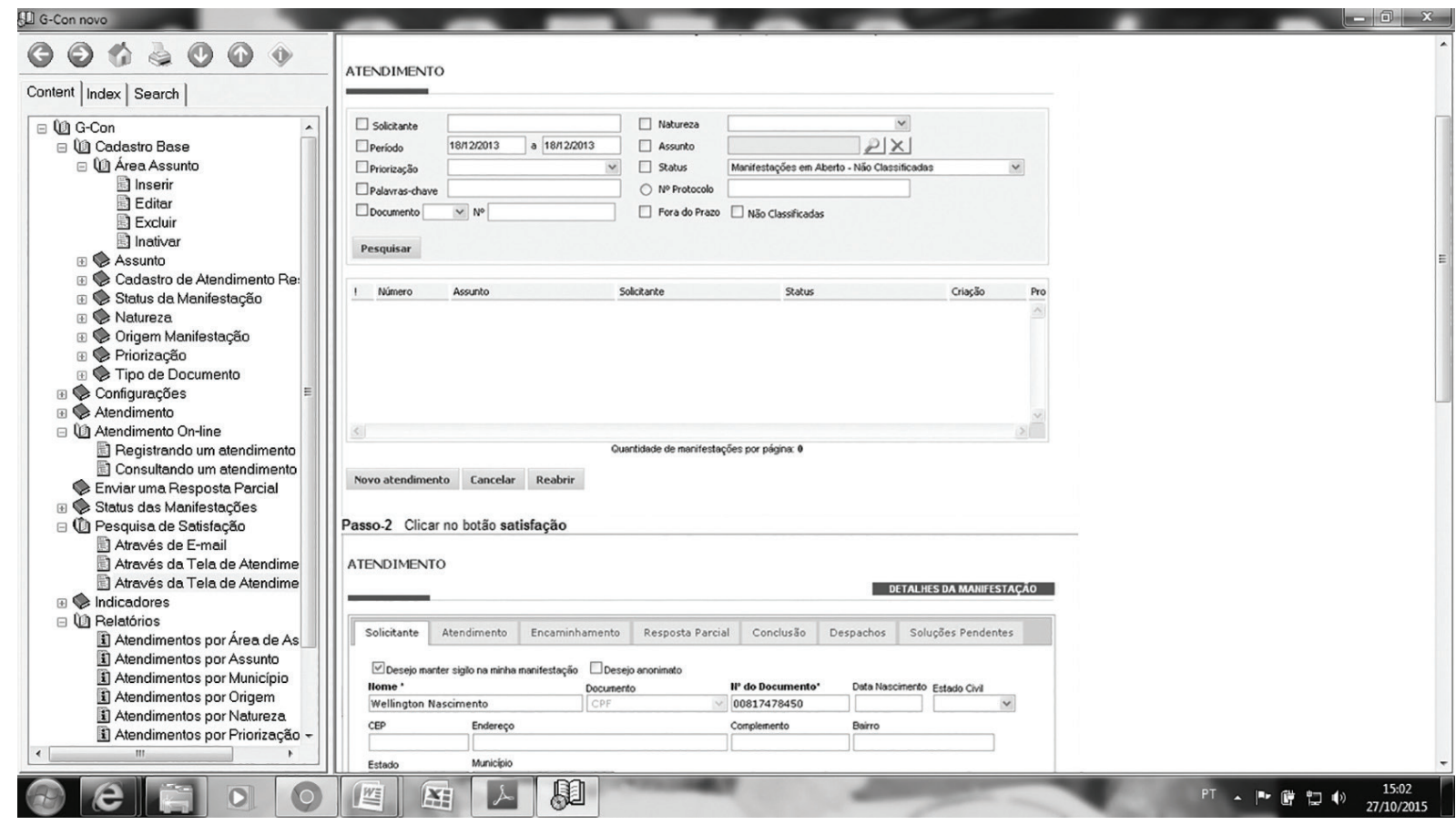

- Permite anexação de documentos (planilhas eletrônicas, textos, imagens etc.) pelo usuário, pessoal do atendimento, Ouvidor e interlocutores nos departamentos.

- Permite classificar o usuário quanto ao tipo (ex: anônimo, servidor, cidadão etc.) e classificar a demanda quanto a Área de Assunto, Assunto, Natureza e Prioridade.

- Possibilita a localização das demandas por vários argumentos de pesquisa, tais como: nome do usuário/interessado, data/período da demanda, número de protocolo, assunto, natureza e palavra-chave, permitindo o cruzamento entre eles.

- Realiza o encaminhamento eletrônico das demandas para os setores, através de e-mail com link para respostas.

- Permite o retorno eletrônico automático dos encaminhamentos pelos interlocutores através de link diretamente para o sistema, com anexação de novos documentos.

- Envia e-mails automáticos aos usuários sobre o andamento e a conclusão, com anexos.

- Realiza pesquisa de satisfação em relação ao atendimento da demanda concluída.

- Possui painel de controle de forma a facilitar o gerenciamento e tratamento das demandas no tocante aos prazos para resolução, através de visualização rápida quanto aos envios, recebimentos e pendências de tratamento, inclusive para as demandas do autoatendimento.

- Gera relatórios dinâmicos e informações estatísticas e indicadores de desempenho da Ouvidoria e da estatística de satisfação dos usuários.

- Permite gerar e imprimir relatórios sintéticos das demandas por vários argumentos, e estes podem ser expandidos até o nível de detalhes da manifestação.

- Possibilita a parametrização dos prazos a serem trabalhados pela Ouvidoria em relação às Respostas Parciais, Encaminhamentos e Pontos de Controle, Despachos, Conclusão das Demandas, Demandas a Vencer e Demandas Vencidas, considerando inclusive os feriados existentes no período. 
Segundo PEPPERS, ROGERS e DORF (2001, p. 46), o verdadeiro poder da integração reside na capacidade de oferecer atendimento diferenciado, portanto é imprescindível que a Ouvidoria esteja bem estruturada e tenha subsídios técnicos para articular-se e integrar-se às demais unidades da instituição em que atua.

O G-CON, Sistema Integrado de Gestão de Ouvidorias do Município do Recife, está disponível na plataforma de dados da EMPREL, Empresa Municipal de Informática, podendo, portanto, ser acessado remotamente de qualquer computador conectado à internet através do endereço http://200.238.107.205:8080/multiwork/controller, o que descentraliza parcialmente o acesso às informações e permite um melhor aproveitamento do parque de máquinas utilizado em função da arquitetura empregada pelo Sistema. O Ouvidor-Geral, de posse de uma senha Master, pode navegar através do Sistema pelos dados e indicadores de todas as secretarias e órgãos, podendo realizar o acompanhamento on-line do trabalho realizado por todos os que fazem parte do Sistema de Ouvidoria.

Para PEPPERS, ROGERS e DORF (2001), a Administração Pública, a partir da utilização de sistemas informatizados, poderá beneficiar o cidadão e a própria gestão, identificando e diferenciando seus "clientes", aprendendo mais sobre eles, no sentido da interatividade constante, e construindo relacionamentos de aprendizados sólidos com cada um.

A Ouvidoria-Geral do Município alinhada com uma gestão transparente elabora relatórios gerenciais que são publicados no site da Ouvidoria com o intuito de fortalecer a transparência do trabalho realizado. O Prefeito e sua equipe de secretários são contemplados com um Relatório consolidado de monitoramento e avaliação qualitativa, destacando pontos como a satisfação do manifestante acerca dos serviços prestados pelo município. No Relatório gerencial consolidado, também existe um campo para análise qualitativa dos pontos fortes e pontos de melhorias identificados no mês, para que esses dados sejam acessados pelos responsáveis das referidas ações.

Com a utilização do Sistema de Gestão, é possível o trabalho integrado dos diversos segmentos do governo: atualmente 15 (quinze) Secretarias 5 (cinco) Órgãos de assessoramento imediato e 8 (oito) Autarquias recebem manifestações encaminhadas via sistema de Ouvidoria e tramitam as manifestações buscando elevar a resolutividade dos atendimentos à população, pois com a devida utilização do Sistema pode-se fluir o atendimento para todo o âmbito municipal de acordo com a sua natureza, envolvendo todos os segmentos responsáveis pela resolução das questões demandadas.

O Sistema de Informações de Ouvidoria tem as seguintes funções: criar base de dados para levantamentos estatísticos; dar tratamento às manifestações dos usuários, controlando prazos; promover o conhecimento sobre o público-alvo e o relacionamento com este, medindo a satisfação com a solução apresentada; e ainda possibilitar a melhoria dos processos organizacionais.

Além das funções citadas acima, o G-CON, Sistema Integrado de Gestão de Ouvidorias, também apresenta as seguintes funcionalidades:

- Acompanha de perto o andamento de suas manifestações, através de um painel de controle.

- Rastreia a manifestação desde o seu registro até o envio da resposta para o manifestante com os detalhes da solução adotada. 
- Monitora todos os encaminhamentos, despachos e respostas realizados pelas secretarias e órgãos.

- Envia respostas parciais e despachos de cobrança automaticamente.

- Gera automaticamente os resultados da Pesquisa de Satisfação, por período e órgãos.

- Dissemina conhecimento entre seus colaboradores, através do banco de informações.

- Mede o grau de satisfação dos usuários dos serviços públicos quanto aos serviços que a atual Ouvidoria-Geral realiza. É fundamental para o monitoramento e a avaliação do nível de eficiência e efetividade desses serviços.

A Pesquisa de Satisfação implantada no Sistema de Ouvidoria contém seis questões do tipo "fechada". É possível o cidadão/usuário respondê-las, através de e-mail, atendimento presencial ou por telefone, após a conclusão da manifestação. Nos Relatórios de Pesquisa de Satisfação junto aos usuários do serviço da Ouvidoria, gerados pela Ouvidoria-Geral do Município do Recife, através do Sistema G-CON, identifica-se:

- Tipo de usuário dos serviços públicos - se é servidor do município ou não.

- A origem de informação a respeito da Ouvidoria: amigos, internet, órgão do governo, mídia ou panfleto.

- Nível de satisfação do manifestante: insatisfatória, parcialmente satisfatória ou satisfatória.

- Papel da Ouvidoria: pouco importante, importante ou muito importante.

- A eficiência da Ouvidoria - demorada, normal ou rápida.

- A reutilização da Ouvidoria - sim ou não.

O ponto forte de uma solução desse porte é poder realizar o cruzamento de informações, possibilitando a identificação de comportamentos antes ocultos pelo grande volume de informações, gerando aprendizado sobre o negócio.

Alguns indicadores sociais trabalhados pela Ouvidoria-Geral do Município do Recife:

- Índice de Resolutividade das manifestações.

- Percentual de representatividade das informações no município.

- Análise geográfica da evolução das manifestações.

- Análise diária.

- Análise mensal da evolução de atendimentos por canal de origem.

- Ranking de secretarias e órgãos que recebem mais denúncias e reclamações.

- Índice de Eficiência do Call Center da Ouvidoria-Geral.

- Evolução da Qualidade do Atendimento ao Cidadão.

- Evolução do Tempo de Resposta ao Cidadão.

- Análise dos Canais de Origem das Manifestações. 


\section{CONSIDERAÇÕES}

Inaugurada em janeiro de 2015, a OGMR, Ouvidoria-Geral do Município do Recife, recebeu até junho de 2017 mais de 24 mil manifestações da população. São denúncias, elogios, pedidos de informação, reclamações e sugestões de quase todos os bairros. Do total computado, a Ouvidoria conseguiu solucionar, dentro do prazo previsto, mais de $70 \%$ das demandas da população. Alguns casos como: Agilidade na marcação de consultas; Melhoria na manutenção e limpeza urbana; Agilidade nos processos de finanças; Melhoria na estruturação de escolas e creches, entre outros resultados apontados no Relatório consolidado, sendo inclusive registrados elogios graças ao retorno dado pela população aos serviços prestados, o que comprova que com a implantação da Ouvidoria houve um avanço na desburocratização dos serviços ofertados à população.

Com base nos dados apresentados, avalia-se que os números são altamente expressivos e positivos, levando-se em consideração o pouco tempo de funcionamento. Esse índice de resolução está dentro dos padrões de Ouvidorias com mais tempo de atividade. Com uma média mensal de mil demandas, recebidas pelos serviços de teleatendimento, correspondência, e-mails ou de forma presencial, a maior parte dos atendimentos refere-se a reclamações, denúncias e solicitação de serviços prestados pelas diversas secretarias e órgãos municipais. É um aparelho estratégico, pois mostra ao cidadão, ao contribuinte, que o Governo Municipal está empenhado em dar uma resposta rápida e segura às demandas recebidas.

A fase de implantação para estruturação da Ouvidoria durou cerca de um ano, percorrendo diversas etapas de licitação, captação de recursos, readequação de espaço físico, aquisição de mobiliários, equipamentos e capacitação da equipe, cumprindo a meta de entregar à população um ambiente estruturado para realizar um atendimento de excelência. A gestão municipal investiu mais de $R \$ 1.500 .000,00$ (Hum milhão e quinhentos mil reais) na estruturação da Ouvidoria-Geral do Município do Recife, dotação orçamentária sob aporte da Secretaria de Governo e Participação Social, à qual a Ouvidoria está vinculada. Para a execução das atividades da Ouvidoria, a equipe passou por um programa de capacitações e orientações quanto aos seus procedimentos, simulações de atendimento e capacitação teórica sobre a gestão municipal e disseminação da cultura de Ouvidoria.

Contudo, são necessários esforços da gestão municipal na manutenção e constantes investimentos em recursos tecnológicos e humanos a fim de proporcionar ao cidadão e/ou servidor uma comunicação efetiva com a gestão, gerando um serviço público de qualidade.

Anteriormente, o único mecanismo que conseguia contabilizar o registro de manifestações era o canal Recife Responde, vinculado à Secretaria de Imprensa, que registrou no ano de 2013 um total de 14.410 demandas, com resolutividade de apenas 38\%, e no ano seguinte, 2014, recebeu 15.240, conseguindo solucionar 44\%; as demais secretarias, órgãos e autarquias não registravam as demandas recebidas, deixando muitas vezes de sistematizar dados estratégicos para a gestão.

Após a implantação da Ouvidoria-Geral do Município, houve no Recife um avanço considerável na questão técnica e, principalmente, no trabalho de disseminação da cultura da Ouvidoria, o que possibilitou a inovação e integração das secretarias e órgãos do Poder Executivo Municipal, interligadas por um único banco de dados que permite gerar on-line informações sobre o desempenho da gestão, possibilitando identificar o nível de satisfação dos usuários desses serviços através da 
Pesquisa de Satisfação. Sem informações precisas e confiáveis, não seria possível ao Município do Recife dimensionar o nível de satisfação quanto aos serviços prestados à população; além disso, o registro de todas as manifestações recebidas pelo Poder Executivo Municipal por meio da Ouvidoria-Geral do Município do Recife poderão subsidiar o próprio monitoramento e avaliação do desempenho dos órgãos e secretarias, contribuindo na formulação e implementação de políticas públicas, tendo como base os relatórios gerenciais. Coube à Ouvidoria-Geral do Município do Recife disseminar a cultura da Ouvidoria nas secretarias e órgãos, por meio do diagnóstico institucional que identificou os gargalos de comunicação existentes nos diversos setores, visando padronizar procedimentos a partir da oficialização da Ouvidoria-Geral. Atualmente a Ouvidoria subsidia tecnicamente por meio de relatórios gerenciais com análise quantitativa e qualitativa e apresenta uma avaliação estratégica dos resultados obtidos, além de capacitar os interlocutores quanto aos procedimentos técnicos que norteiam as ações da Ouvidoria, conforme modelo conceitual de Ouvidoria adotado pelo Município do Recife. Com a consolidação da Ouvidoria-Geral, torna-se mais eficaz o processo de intercâmbio e comunicação entre o cidadão e/ou servidor e o Município, possibilitando uma maior transparência e prestação de contas dos seus resultados.

Entende-se, portanto, que o município apresenta atualmente, com seus investimentos para a consolidação de um ambiente de Ouvidoria, um bom grau de amadurecimento nas atividades de conhecimento e processo, de integração entre os órgãos e secretarias; e os profissionais envolvidos diretamente no processo apresentam um excelente conhecimento dos procedimentos, comprometimento e responsabilidade; e existe uma estrutura física e de equipamentos próprios para apoio ao processo; também são disponibilizados diversos canais de acesso para o cidadão como: E-mail, Teleatendimento com o serviço de 0800, Correspondência, Telefone, Atendimento Presencial, Site. Todas as manifestações recebidas por esses canais são registradas e interligadas por um único banco de dados, por meio de um sistema que possibilita gerar on-line informações sobre o desempenho dos setores e averiguar o nível de satisfação dos usuários desses serviços.

\section{REFERÊNCIAS}

JÚNIOR, Humberto Viana. Ouvidoria-Geral UNIFACS: O Ombudsman nas instituições particulares de ensino superior. Disponível em: www.unisc.br/fnou/artigos/Ombusdman.pdf. Acesso em: 10 jun. 2017.

MATSUDA. Teoria dos sistemas. Disponível em: Site.mpc.com.br/gberaldo/Teoria\%20dos\%20sistemas.pdf. Acesso em: 10 jun. 2017

PEPPERS, Don; ROGERS, Martha; DORF, Bob. Marketing One to One: Ferramentas para implantação de programas de marketing one to one. Tradução de Ernesto Yoshida e Maria Cristina Vondriak. Revisão de Ignês Capozzi. São Paulo: Makron Books, 2001. p. 46.

POLLONI, Enrico G.F. Administrando sistemas de Informação. São Paulo: Editora Futura, 2000. p. 30. 